\title{
Effects of TiAl Alloy as a Binder on Cubic Boron Nitride Composites
}

\author{
Yuxi Liu, Wei Zhang* * , Yingbo Peng, Guojiang Fan and Bin Liu
}

check for updates

Citation: Liu, Y.; Zhang, W.; Peng, Y.; Fan, G.; Liu, B. Effects of TiAl Alloy as a Binder on Cubic Boron Nitride Composites. Materials 2021, 14, 6335. https://doi.org/10.3390/ma14216335

Academic Editor: Hajo Dieringa

Received: 9 September 2021

Accepted: 18 October 2021

Published: 23 October 2021

Publisher's Note: MDPI stays neutral with regard to jurisdictional claims in published maps and institutional affiliations.

Copyright: (c) 2021 by the authors. Licensee MDPI, Basel, Switzerland. This article is an open access article distributed under the terms and conditions of the Creative Commons Attribution (CC BY) license (https:// creativecommons.org/licenses/by/ $4.0 /)$.
State Key Laboratory of Powder Metallurgy, Central South University, Changsha 410083, China; yuxiliu@csu.edu.cn (Y.L.); ybpengnj@njau.edu.cn (Y.P.); guojiang.fan@gmail.com (G.F.); binliu@csu.edu.cn (B.L.) * Correspondence: waycsu@csu.edu.cn

\begin{abstract}
Owing to their extreme hardness, cubic boron nitride (cBN) composites are widely used in cutting applications. The performance of $\mathrm{cBN}$ composites is closely related to the characteristics of the binder. Therefore, novel binders must be developed to improve the performance of cBN composites. In the present work, TiAl intermetallics were used as binders to fabricate cBN composites by employing a high-temperature and high-pressure sintering method. The phase transformation, sintering reaction mechanism, thermal stability, and mechanical properties of the resultant cBN composites were investigated. It was found that during the sintering process, Ti atoms preferentially reacted with boron nitride particles, whereas $\mathrm{Al}$ atoms enriched and transformed into $\mathrm{TiAl}_{3}$ phases and formed $\mathrm{cBN} / \mathrm{AlN}, \mathrm{AlB}_{2} / \mathrm{TiN}$, and $\mathrm{TiB}_{2} / \mathrm{TiAl}_{3}$-layered structures eventually. The composites maintained good oxidation resistance at $1200{ }^{\circ} \mathrm{C}$. A decrease in the particle size of the TiAl binder improved the uniformity of particle size distribution and increased the flexural strength of the composites.
\end{abstract}

Keywords: cubic boron nitride; TiAl alloy; high-temperature and high-pressure sintering method; flexural strength

\section{Introduction}

Cubic boron nitride (cBN) has excellent hardness, wear resistance, thermal stability, and chemical inertness. In order to manufacture polycrystalline cubic boron nitride (PcBN), binders are generally used [1,2]. Traditional PcBN binders mainly include metallic binders (titanium, aluminum, cobalt, and their alloys), ceramic binders (nitrides, carbides, and silicides), and cermet binders, represented by MAX phases, where $M$ is an early transition metal, $\mathrm{A}$ is an A-group element (mostly IIIA and IVA), and $\mathrm{X}$ is either $\mathrm{C}$ and/or $\mathrm{N}[3,4]$. However, these binders have some serious disadvantages. For example, $\mathrm{Al}$ atoms can react with $\mathrm{cBN}$ to form $\mathrm{AlB}_{2}$ and $\mathrm{AlN}$. Moreover, residual $\mathrm{Al}$ atoms cause the thermo-softening of PcBN. The addition of Ti converts $\mathrm{AlB}_{2}$ into harder $\mathrm{AlN}$ and $\mathrm{TiB}_{2}$ phases; however, the combustion reaction of $\mathrm{Ti}$ and $\mathrm{Al}$ commonly transforms cBN into hBN due to the local high temperature. When MAX phases, such as $\mathrm{Ti}_{3} \mathrm{AlC}_{2}$ and $\mathrm{Ti}_{3} \mathrm{SiC}_{2}$, are used to sinter $\mathrm{PcBN}_{\mathrm{C}}$ they decompose under high temperatures and high pressure. The formation of reaction products is difficult to control in this case [5-8]. Therefore, a binder that takes advantages of both metallic and ceramic binders is a potential material to substitute for traditional binders for superior PcBN performance.

Intermetallic compounds generally consist of both ionic and covalent bonds; thus, they possess the characteristics of metals and ceramics at the same time. Intermetallic compounds are the best potential high-temperature materials between superalloys and ceramics. $\gamma$-TiAl, a lightweight, high-temperature intermetallic compound, has the advantages of low density, high specific strength, superb corrosion resistance, high-temperature resistance, and excellent oxidation and fatigue resistance. Thus, it is widely applied in the aerospace and automotive industries [9-11]. In comparison to other intermetallic compounds, $\gamma$-TiAl has a higher oxidation resistance, a higher specific melting point, and superior high-temperature stability. Hence, it is considered as a potential PcBN binder. 
TiAl alloy has not been adopted as a PcBN binder so far; however, an intermetallic compound of $\mathrm{Ti}$ and $\mathrm{Al}$ is produced during the sintering process of PcBN [12,13]. The use of the pre-alloyed TiAl intermetallic compound as a PcBN binder has the following advantages: (1) although TiAl is intrinsically brittle at room temperature, it has enough strength and toughness at high temperatures to avoid thermo-softening. (2) TiAl can react with $\mathrm{cBN}$ to generate high-strength $\mathrm{TiB}_{2}, \mathrm{TiN}, \mathrm{AlB}_{2}$, and $\mathrm{AlN}$ phases, which can adequately bond cBN particles [14]. (3) The combustion reaction of Ti and Al powder particles does not occur during the sintering process, thereby preventing the local temperature from rising to form hBN. (4) Solid-phase sintering makes the distributions of $\mathrm{Al}$ and Ti more uniform and the sintering structure more consistent. (5) TiAl can maintain the intermetallic structure during the sintering process and form a matrix-reaction product-intermetallic compound, which help to retain the advantages of using a metallic binder for a complete bonding. This process can avoid the presence of metal residues and maintain good mechanical properties at high temperatures. Moreover, the distribution of reaction products is controllable during this process. It should be noted that $\mathrm{TiAl}$ is easily oxidized during the high-temperature sintering. Thus, the oxygen level needs to be strictly controlled during the entire process. Solid-phase sintering also requires particle uniformity; otherwise, a large number of pores without binder filling exist, which act as crack-propagation channels.

The current study presents the results of using high-temperature and high-pressure sintering to prepare PcBN composites by using TiAl as a binder. The type and distribution of sintered products were clarified. The sintering mechanism and the effects of the grain sizes of binder particles on the uniformity and controllability of PcBN structures were systematically investigated.

\section{Materials and Methods}

cBN composites were prepared by combining pre-alloyed $\mathrm{Ti}-48 \mathrm{Al}-2 \mathrm{Cr}-2 \mathrm{Nb}$ powder (purity $>99 \%,-150$ mesh) and cBN powder (purity $>99 \%,<10 \mu \mathrm{m}$ ). Stainless steel tanks and balls were used. The TiAl powder was weighed with a ball-to-powder ratio of 15:1, placed in a ball mill under the protection of argon for dry milling (at $200 \mathrm{r} / \mathrm{min}$ for $15 \mathrm{~h}$ and at $250 \mathrm{r} / \mathrm{min}$ for $15 \mathrm{~h}$ and $20 \mathrm{~h}$ ) and in ethanol for wet milling (at $250 \mathrm{r} / \mathrm{min}$ for $15 \mathrm{~h}$ and $300 \mathrm{r} / \mathrm{min}$ for $25 \mathrm{~h}$ ), and mixed with the cBN powder for six hours to ensure uniformity. The TiAl powder initial weight ratio was 10\%. The phase compositions of the TiAl powder before and after ball milling were detected by X-ray diffraction (XRD) The mixed powder was sintered at $1400{ }^{\circ} \mathrm{C}$ under a pressure of $5 \mathrm{GPa}$ for $30 \mathrm{~min}$ to obtain a cBN composite sample.

The sintered samples were then cut and polished by a diamond grinding disc. The densities of the composite samples were measured by Archimedes' principle. The phase compositions of the synthesized samples were analyzed by an XRD (Max255Ovb+, RigakuD, Tokyo, Japan) under $\mathrm{Cu}-\mathrm{K} \alpha$ radiation. The microscopic morphologies of the samples were revealed by a scanning electron microscope (SEM; Nova NanoSEM230, FEI, Hillsboro, OR, USA, VEGA3-SBH, TESCAN, Brno, Czech Republic) equipped with an energy-dispersive spectroscope (EDS). Raman spectroscopy (LabRAM HR800, Horiba Jobin Yvon, Paris, France) was performed to analyze bonding characteristics between different atoms. Elemental distributions were analyzed by an electron probe micro-analyzer (EPMA; Jxa-8530F, JEOL, Tokyo, Japan). The thermal analysis of the samples was performed by a synchronous thermal analyzer (STA 449 F3 Jupiter, NETZSCH, Selb, Germany), and their flexural strengths were measured by an mechanical testing machine (Instron 3369, Boston, MA, USA).

\section{Results}

\subsection{Phase and Microstructure}

It is difficult for commercial TiAl powder to be used as a binder due to larger particle size (particle size of general binders is less than $10 \mu \mathrm{m}$ ); ball milling was used to crush the TiAl powder to facilitate sintering. The particle morphology of the TiAl powder after 
ball milling is displayed in Figure 1, and the corresponding XRD pattern is presented in Figure 2. Figure $1 \mathrm{~b}-\mathrm{d}$ describe the dry-milled TiAl powder, while Figure $1 \mathrm{e}, \mathrm{f}$ show the wet-milled powder. TiAl powder particles were spherical before ball milling, and the powders after ball milling were composed of rough-surface and irregular blocks or granular particles. Owing to the cold welding of the dry-milled powder, some of the finer debris agglomerated, and some coarse and massive particles possessed a multilayered structure. The wet-milled powders were ruptured into fine flakes. The corresponding full width at half maximum of the XRD peak increased.
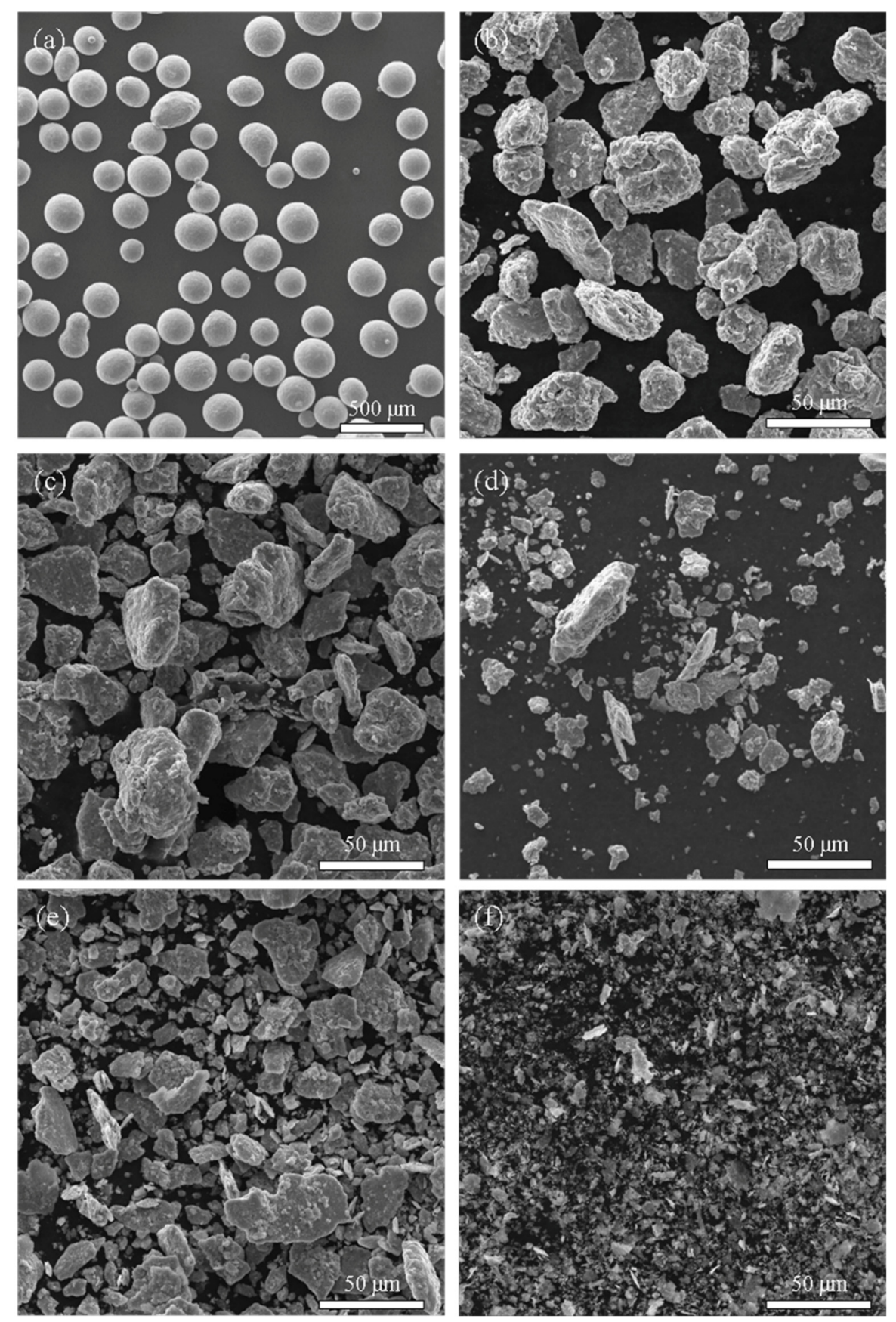

Figure 1. Surface morphologies of TiAl powder: (a) primary powder, (b) ball-milled powder at $200 \mathrm{r} / \mathrm{min}$ for $15 \mathrm{~h}$ (particle size $=29 \mu \mathrm{m}$ ), (c) ball-milled powder at $250 \mathrm{r} / \mathrm{min}$ for $15 \mathrm{~h}$ (particle size $=26 \mu \mathrm{m}),(\mathrm{d})$ ball-milled powder at $250 \mathrm{r} / \mathrm{min}$ for $20 \mathrm{~h}$ (particle size $=17 \mu \mathrm{m})$, (e) ballmilled powder at $250 \mathrm{r} / \mathrm{min}$ for $15 \mathrm{~h}$ (particle size $=15 \mu \mathrm{m}$ ), (f) ball-milled powder at $300 \mathrm{r} / \mathrm{min}$ for $25 \mathrm{~h}$ (particle size $=5 \mu \mathrm{m})$. (b-d) dry-milled, $(\mathbf{e}, \mathbf{f})$ wet-milled. 


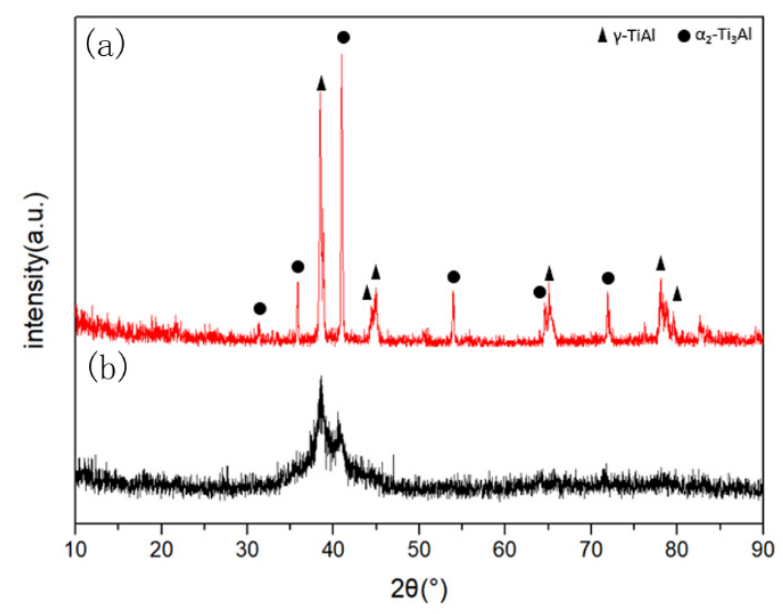

Figure 2. XRD spectra of TiAl powder: (a) primary powder, (b) ball-milled powder for $15 \mathrm{~h}$ (particle size $=26 \mu \mathrm{m}$ ).

The relative density of the sintered cBN composites reached 99\%. Their XRD patterns are exhibited in Figure 3. The phase structures of the sintered $\mathrm{cBN}$ composites were composed of a majority of $\mathrm{cBN}$ phases, as well as $\mathrm{TiN}, \mathrm{TiB}_{2}, \mathrm{AlN}, \mathrm{AlB}_{2}$, and $\mathrm{TiAl}_{3}$ phases. However, $\mathrm{TiAl}$ and $\mathrm{Ti}_{3} \mathrm{Al}$ phases that existed in the original TiAl powder were not observed in the sintered cBN composites. As the particle size of the binder decreased, the XRD peaks gradually broadened, and the $\mathrm{TiAl}_{3}$ phase disappeared eventually.

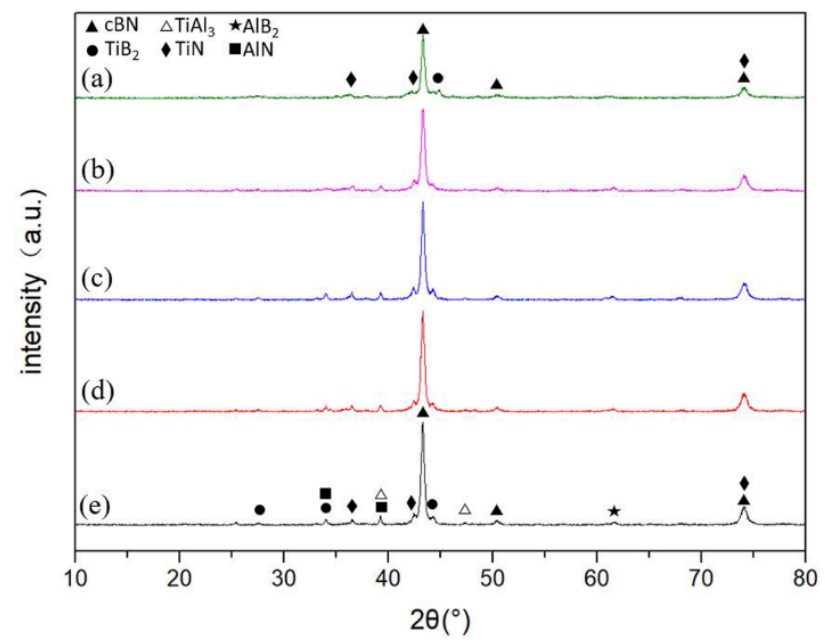

Figure 3. XRD spectra of sintered cBN composites: (a) $5 \mu \mathrm{m}$, (b) $15 \mu \mathrm{m}$, (c) $17 \mu \mathrm{m}$, (d) $26 \mu \mathrm{m}$, (e) $29 \mu \mathrm{m}$.

To clarify the morphology and composition of the binder after sintering, the binderrich region was examined by the SEM. Figure 4a presents the SEM images of the cBN composites, with an average binder particle size of $15 \mu \mathrm{m}$. In the microstructures, original white and gray TiAl regions were distributed within the black cBN matrix. An Al-rich white area appeared at the center of the original TiAl region, and a Ti-rich gray reactiondiffusion layer existed between the white area and the $\mathrm{CBN}$ matrix. A very thin Al-rich layer appeared between the diffusion layer and the cBN matrix. 

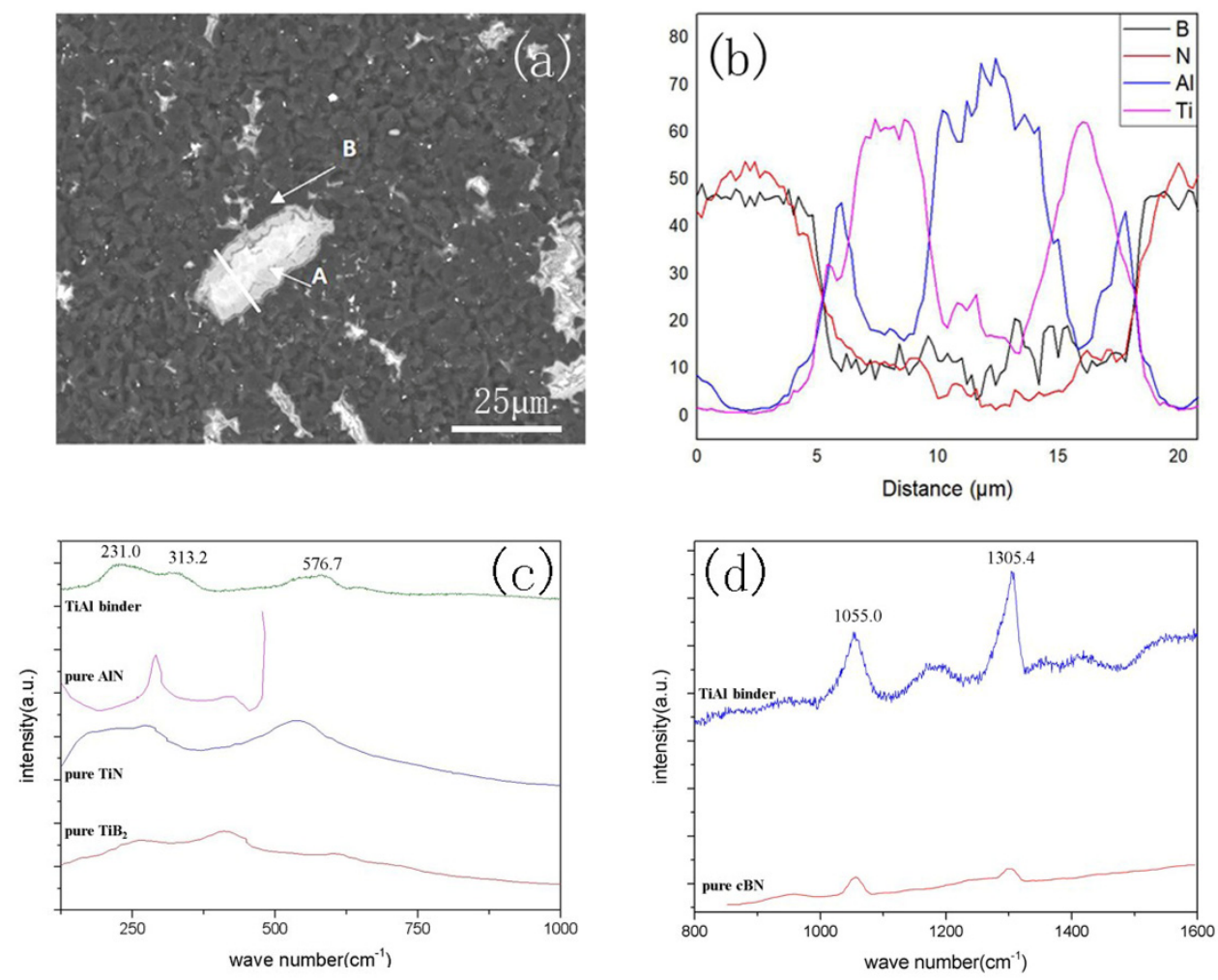

Figure 4. Microstructure and phase analysis of cBN composites: (a) $15 \mu \mathrm{m}$, (b) EDS of the line in (a), (c) Raman spectra of point A in (a), (d) Raman spectra of point B in (a).

A Raman spectroscopy analysis was performed on points A and B in Figure 4a, and the corresponding results are presented in Figure $4 \mathrm{c}, \mathrm{d}$, respectively. At point $\mathrm{A}$ of the diffusion layer, the peaks at $231.0 \mathrm{~cm}^{-1}$ [15], $313.2 \mathrm{~cm}^{-1}$ [16], and $576.7 \mathrm{~cm}^{-1}$ [17] appeared from $\mathrm{TiB}_{2}, \mathrm{AlN}$, and TiN, respectively. At point $\mathrm{B}$, the peaks at $1055.0 \mathrm{~cm}^{-1}$ and $1305.4 \mathrm{~cm}^{-1}[18]$ originated from $\mathrm{CBN}$. The main bonding in the composite sample were Ti-B and Al-N. The peaks of Ti-rich compounds were much higher than those of Al-rich compounds, indicating that the content of nitrides and borides in Ti was much higher than in Al.

An EPMA analysis was performed on each point in Figure 5a. The corresponding results are presented in Table 1 . The white phases surrounded by the diffusion layer are indicated by $1 \#$ and $3 \#$ (Figure 5a). In these areas, the content of $\mathrm{Al}$ was high, whereas the contents of $\mathrm{B}$ and $\mathrm{N}$ were low, indicating that these areas were mainly composed of $\mathrm{TiAl}_{3}$. The phases of the gray diffusion layer are indicated by $2 \#$ and $4 \#$ (Figure 5a). The content of Ti in these areas was significantly higher than in other regions. The contents of $\mathrm{B}$ and $\mathrm{N}$ were also high in the diffusion layer. Thus, it is concluded that Ti was rapidly consumed to form a large portion of the $\mathrm{TiB}_{2}$ and $\mathrm{TiN}$ phases. Figure $5 \mathrm{e}$ shows that the $\mathrm{Nb}$ elements were distributed in the center of the original $\mathrm{TiAl}$ area and hardly diffused to the matrix. There was no phase that contained $\mathrm{Nb}$ in the XRD spectra, which means that $\mathrm{Nb}$ was solubilized in the $\mathrm{TiAl}_{3}$ phase. The line scan in Figure $4 \mathrm{~b}$ indicates that when the EDS signal moved from the matrix to the original TiAl region, $\mathrm{B}$ and $\mathrm{N}$ content decreased, whereas $\mathrm{Al}$ and Ti content increased. $\mathrm{Al}$ content reached the first peak ahead of $\mathrm{Ti}$, and then the $\mathrm{Al}$ content gradually decreased, while the Ti content maximized. The existence of $\mathrm{AlN}$ and $\mathrm{AlB}_{2}$ peaks in the XRD spectra and the presence of Al-N peaks in the Raman spectrum indicate that the nitrides and borides of $\mathrm{Al}$ were distributed in the thin $\mathrm{Al}$-rich region against the black matrix and formed $\mathrm{cBN} / \mathrm{AlN}, \mathrm{AlB}_{2} / \mathrm{TiN}$, and $\mathrm{TiB}_{2} / \mathrm{TiAl}_{3}$-layered structures, as showed in Figure 5b. 


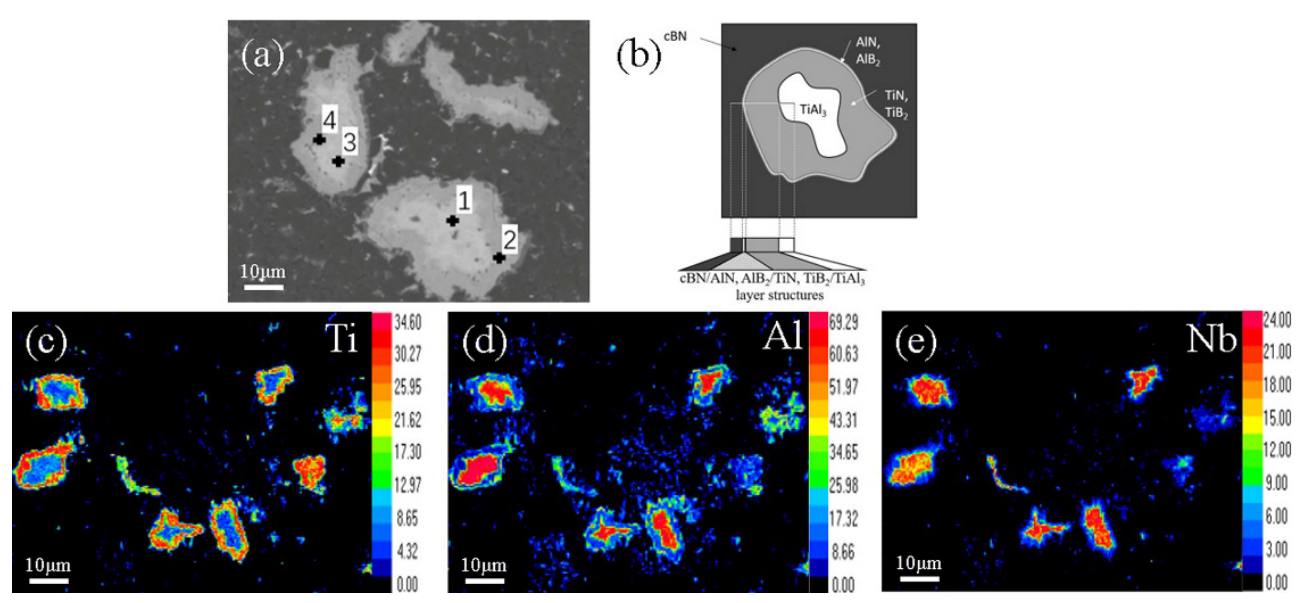

Figure 5. Microzonal composition analysis and EPMA results of cBN composites: (a) microzonal composition analysis; (b) layer structure of cBN composite; (c) EPMA map of Ti element; (d) EPMA map of Al element; (e) EPMA map of Nb element.

Table 1. Microzonal composition analysis of cBN composites in Figure 5.

\begin{tabular}{cccccc}
\hline Point & Ti & Al & B & N & Nb \\
\hline 1 & 11.67 & 53.10 & 19.20 & 3.47 & 12.56 \\
2 & 27.18 & 15.49 & 31.60 & 24.18 & 1.55 \\
3 & 12.13 & 67.29 & 0.00 & 6.22 & 14.35 \\
4 & 32.14 & 8.92 & 22.43 & 34.90 & 1.60 \\
\hline
\end{tabular}

\subsection{Sintering Mechanism}

The bonding mechanism of TiAl and $\mathrm{cBN}$ was compared with that between $\mathrm{cBN}$ and traditional binders. Li et al. [19] sintered $c B N-A l$ in the high-temperature range of $800-1400{ }^{\circ} \mathrm{C}$ at $5 \mathrm{GPa}$. It was found that $\mathrm{Al}$ reacted with $\mathrm{cBN}$ to form $\mathrm{AlN}$ at $900{ }^{\circ} \mathrm{C}$, and free $\mathrm{B}$ atoms diffused to form $\mathrm{AlB}_{2}$.

$$
\begin{gathered}
\mathrm{BN}+\mathrm{Al} \rightarrow \mathrm{AlN}+[\mathrm{B}] \\
2[\mathrm{~B}]+\mathrm{Al} \rightarrow \mathrm{AlB}_{2}
\end{gathered}
$$

Rong et al. $[20,21]$ studied the microstructure of cBN-Al by TEM and reported that the relative content of $\mathrm{cBN}$ had an important effect on the reaction pathway. When the $\mathrm{cBN}$ content ranged between 80 and $90 \%, \mathrm{AlB}_{12}$ was formed. $\mathrm{Al}$ atoms first filled the pores between $\mathrm{cBN}$ grains and then reacted with $\mathrm{cBN}$ grain surfaces to form AlN. B atoms, which were released by BN, diffused through the AlN layer and reacted with unreacted $\mathrm{Al}$ to form $\mathrm{AlB}_{2}$ and $\alpha-\mathrm{AlB}_{12}$. When TiN was added, $\mathrm{AlB}_{2}$ with poor properties reacted with TiN to form harder $\mathrm{AlN}$ and $\mathrm{TiB}_{2}$ phases. Finally, cBN reacted with $\mathrm{AlN}$, TiB 2 , and TiN phases to form a three-dimensional network matrix, which effectively improved the bonding between the binder and the $\mathrm{cBN}$ grains.

$$
\begin{gathered}
\mathrm{AlB}_{2}+\mathrm{TiN} \rightarrow \mathrm{AlN}+\mathrm{TiB}_{2} \\
2 \mathrm{BN}+\mathrm{TiN}+3 \mathrm{Al} \rightarrow 3 \mathrm{AlN}+\mathrm{TiB}_{2}
\end{gathered}
$$

Deng [22] asserted that $\mathrm{Al}$ could react aggressively with $\mathrm{Ti}$ to form intermetallic compounds, which can generate excessive heat within a very short period time. This abrupt heating process reversely transformed a part of cBN into hBN. Active $\mathrm{Al}$ and $\mathrm{Ti}$ atoms in liquid $\mathrm{TiAl}, \mathrm{TiAl}_{3}$, and $\mathrm{Ti}_{3} \mathrm{Al}$ reacted with $\mathrm{cBN}$. hBN was gradually converted to cBN, with AlN as a catalyst. 
When the MAX phase of $\mathrm{Ti}_{3} \mathrm{AlC}_{2}$ is used as a binder and the content of $\mathrm{cBN}$ is low, $\mathrm{Ti}_{3} \mathrm{AlC}_{2}$ decomposes very minimally [6].

$$
\mathrm{Ti}_{3} \mathrm{AlC}_{2} \rightarrow \mathrm{Ti}_{3} \mathrm{C}_{2}+[\mathrm{Al}]
$$

The formation of $\mathrm{TiC}$ can isolate $\mathrm{cBN}$ and $\mathrm{Ti}_{3} \mathrm{AlC}_{2}$, which prevents further reactions between them. A larger amount of $\mathrm{cBN}$ increases the contact area between the substrate and $\mathrm{Ti}_{3} \mathrm{AlC}_{2}$. The following reaction continues to occur until the transition layer fully grows.

$$
\mathrm{Ti}_{3} \mathrm{C}_{2} \rightarrow 2 \mathrm{TiC}+[\mathrm{Ti}]
$$

Free $\mathrm{Ti}$ and $\mathrm{Al}$ atoms react with $\mathrm{cBN}$, and $\mathrm{Ti}_{3} \mathrm{AlC}_{2}$ is consumed continuously until it completely decomposes.

In the present study, after the high-temperature and high-pressure sintering, the composite was mainly composed of cBN and some newly formed ceramic phases $\left(\mathrm{TiB}_{2}\right.$, AlN). The main reactions that occurred during the sintering process are presented below.

$$
\begin{gathered}
3 \mathrm{TiAl}+2 \mathrm{BN} \rightarrow \mathrm{TiB}_{2}+2 \mathrm{TiN}+3[\mathrm{Al}] \\
3[\mathrm{Al}]+2 \mathrm{BN} \rightarrow \mathrm{AlB}_{2}+2 \mathrm{AlN}
\end{gathered}
$$

It was not found that $\alpha-\mathrm{AlB}_{12}$ was present in the final phase composition. Although $\alpha-\mathrm{AlB}_{12}$ was more stable than $\mathrm{AlB}_{2}$ at high temperatures, $\alpha-\mathrm{AlB}_{12}$ would appear when the molar content of $\mathrm{Al}$ was over $40 \%$. In this work, the TiAl powder initial weight ratio was $10 \%$, which was much less than $40 \%$.

A thermodynamic analysis was performed to reveal the reactions of Ti and Al with the matrix.

$$
\begin{gathered}
3 \mathrm{Al}+2 \mathrm{BN} \rightarrow \mathrm{AlB}_{2}+2 \mathrm{AlN} \\
3 \mathrm{Ti}+2 \mathrm{BN} \rightarrow \mathrm{TiB}_{2}+2 \mathrm{TiN}
\end{gathered}
$$

The fitting free energy curves of reactions (9) and (10) are displayed in Figure 6 [23].

$$
\begin{gathered}
\Delta G_{T}^{\Theta}(\mathrm{Ti})=-492,353+24.78 T(298-1200 \mathrm{~K}) \\
\Delta G_{T}^{\Theta}(\mathrm{Al})=-203,740+50.35 T(298-1200 \mathrm{~K})
\end{gathered}
$$

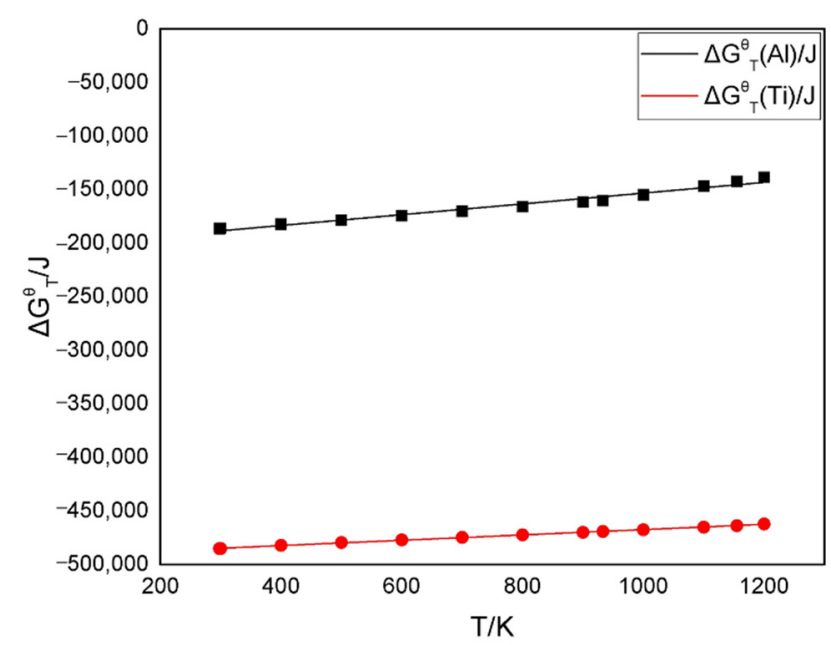

Figure 6. Fitting function curves of the Gibbs free energy.

When TiAl was bonded with cBN, the reaction between Ti and cBN was much more active than that between $\mathrm{cBN}$ and $\mathrm{Al}$. Ti atoms in the lattice first reacted with $\mathrm{cBN}$ to form $\mathrm{TiN}$ and $\mathrm{TiB}_{2}$ and then attracted more $\mathrm{Ti}$ atoms to aggregate. $\mathrm{Al}$ atoms were continuously 
rearranged to both sides of the particle. Al atoms, which were located inside of the particle, were continuously enriched. A large amount of $\mathrm{TiAl}_{3}$ was replaced by $\mathrm{Al}$ atoms. $\mathrm{Al}$ atoms near the boundary reacted with cBN to further bond the particle.

During the heating process of sintering, $\mathrm{Al}$ first reached the melting point $\left(660^{\circ} \mathrm{C}\right)$. The molten $\mathrm{Al}$ penetrated cBN gaps, which wrapped and isolated Ti from the matrix to a certain extent and generated Al nitrides and borides. An AlN melt film was formed on the cBN surface to bond the matrix, resulting in the formation of PcBN with high density and good toughness [18,24]. The MAX phase first decomposed into Al atoms, which reacted with the matrix. A further decomposition produced Ti atoms during sintering. The reaction mechanism is presented in Table 2.

Table 2. Reaction mechanisms of several binders.

\begin{tabular}{cccc}
\hline Binder Type & Preferred Element & Sintering Type & Local Heating \\
\hline $\mathrm{Ti}+\mathrm{Al}$ & $\mathrm{Al}$ & liquid-state & $\sqrt{ }$ \\
$\mathrm{Ti}_{3} \mathrm{AlC}{ }_{2}$ & $\mathrm{Al}$ & solid-state & $\times$ \\
$\mathrm{TiAl}$ & $\mathrm{Ti}$ & solid-state & $\times$ \\
\hline
\end{tabular}

After the alloying of $\mathrm{Ti}$ and $\mathrm{Al}$, the reaction order changed. A large amount of $\mathrm{Ti}$ nitrides and borides were selectively generated. The explosive combustion reaction of $\mathrm{Ti}$ and $\mathrm{Al}$ to cause $\mathrm{cBN}$ reversal into $\mathrm{hBN}$ was avoided.

\subsection{Properties Analysis}

A thermal analysis was performed on the cBN composite, with an average TiAl particle size of $15 \mu \mathrm{m}$. Its TG-DSC (Thermo Gravimetry-Differential Scanning Calorimetry analysis) curve and pure cBN abrasives are displayed in Figure 7 . The $-0.49 \%$ mass loss in the early stage of the TG curve occurred due to the desorption of the adsorbed gas in the composite during the heating stage. The sample was then slowly oxidized to a temperature of $1206^{\circ} \mathrm{C}$, and subsequently, the oxidation process accelerated. At this time, the oxidation and evaporation of the sample proceeded simultaneously. The weight gain during oxidation was much greater than that during evaporation. The maximum weight loss occurred at $1298{ }^{\circ} \mathrm{C}$. The surface oxide film began to break, and a large amount of oxygen entered the interior of the composite and quickly reacted with cBN. Finally, a large amount of substrate reacted at $1386^{\circ} \mathrm{C}$. Compared with pure $c B N$ abrasives, the sample had less weight gain at a temperature of nearly $1250{ }^{\circ} \mathrm{C}[25]$.

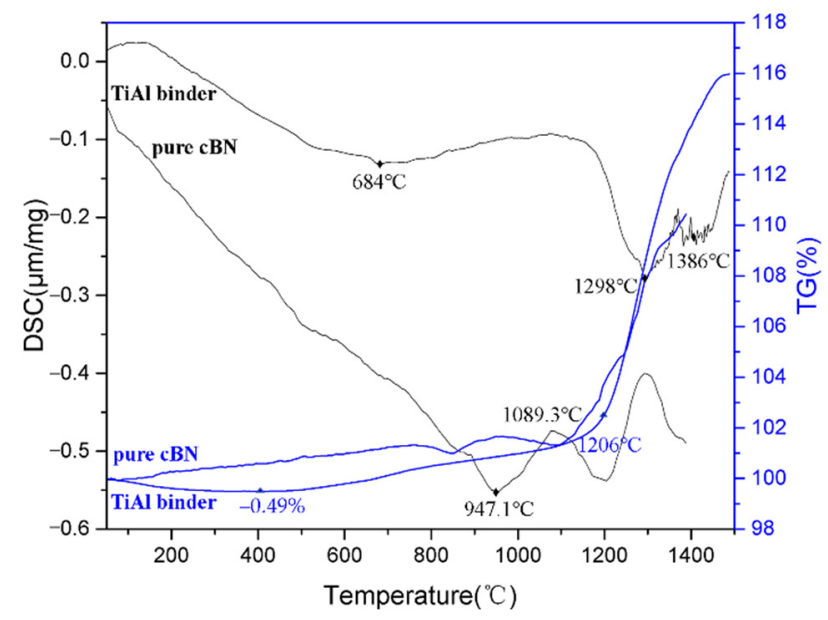

Figure 7. TG-DSC curves of the $\mathrm{cBN}$ composite $(15 \mu \mathrm{m})$ and pure $\mathrm{cBN}$ abrasives.

The flexural strength of the $\mathrm{cBN}$ composites with different TiAl particle sizes are presented in Table 3. It is clear that as the TiAl particle size decreased, the flexural strength increased significantly. Different ball milling methods also caused a change in flexural 
strength. The oxygen content in the wet-milled samples increased significantly, resulting in a decrease in the flexural strength. The highest flexural strength was obtained when the TiAl particle size was $5 \mu \mathrm{m}$. The SEM images of the cBN composite with different particle size are displayed in Figure 8.

Table 3. Flexural strengths of cBN composites.

\begin{tabular}{cccc}
\hline NO. & TiAl Particle Size/ $\mathbf{m m}$ & Ball Milling Method & Flexural Strength/MPa \\
\hline 1 & 29 & dry & 99 \\
2 & 26 & dry & 101 \\
3 & 17 & dry & 182 \\
4 & 15 & wet & 170 \\
5 & 5 & wet & 360 \\
\hline
\end{tabular}
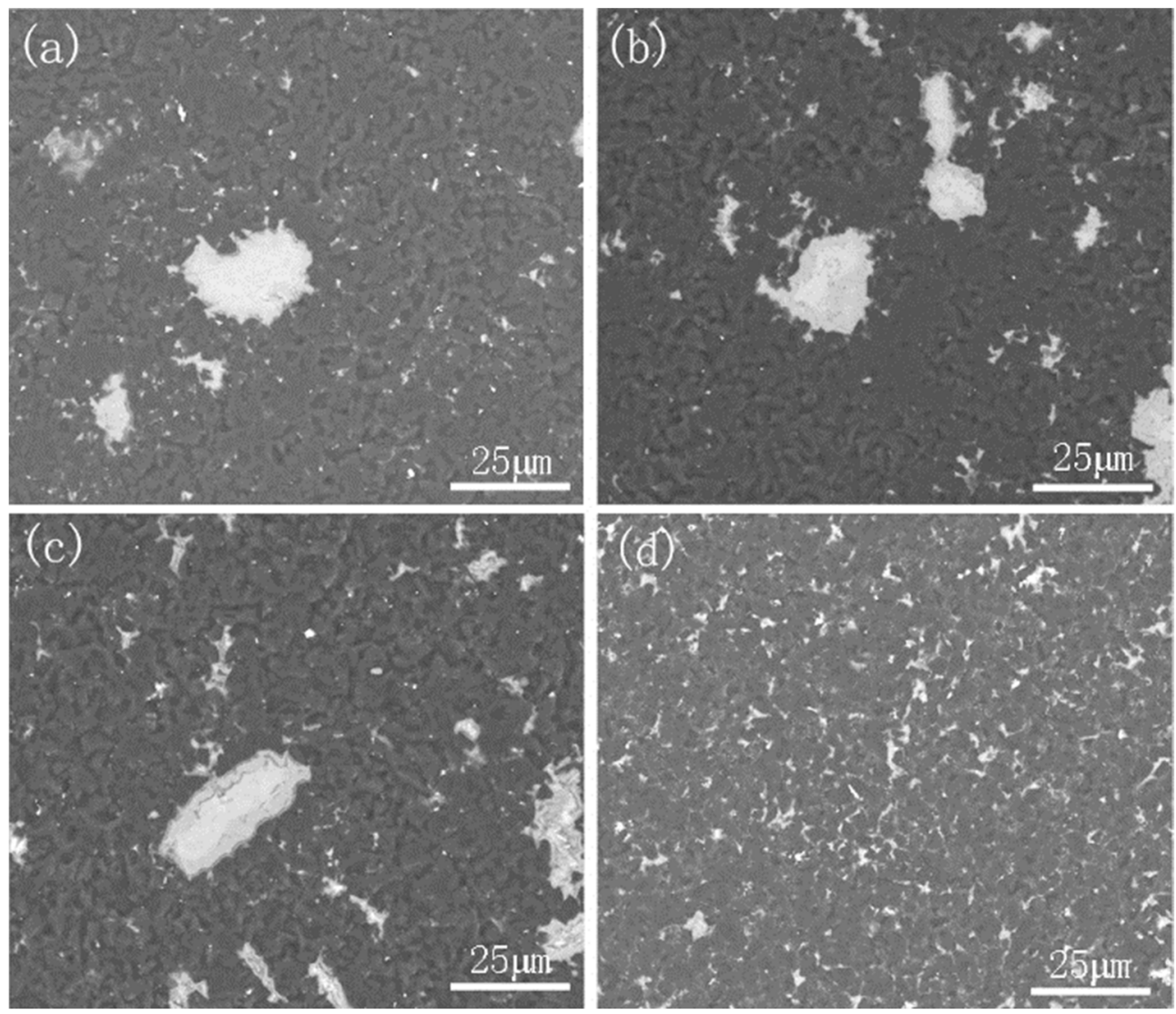

Figure 8. Backscattered electron images of cBN composites: (a) $29 \mu \mathrm{m}$, (b) $17 \mu \mathrm{m}$, (c) $15 \mu \mathrm{m}$, (d) $5 \mu \mathrm{m}$.

The fracture morphology of the three-point-bending samples of the cBN, with an average TiAl particle size of $5 \mu \mathrm{m}$, is displayed in Figure 9. The cBN matrix had a typical rock sugar-like intercrystalline fracture morphology, and the crystal interface at the position of the binder was not obvious. The AlN phase was observed at gray cBN grain boundaries, and the $\mathrm{TiB}_{2}$ ceramic phase was observed in the diffusion layer. At the same time, as TiAl can still maintain a certain strength at a relatively high temperature, it could avoid thermo-softening caused by metal residues. However, as TiAl alloy has a higher melting point than $\mathrm{Al}$, when the particle size was large, the gaps between $\mathrm{cBN}$ particles could not be completely filled. These unfilled gaps had a certain effect on the initiation and propagation of cracks, thereby affecting the toughness and density of the composite. 

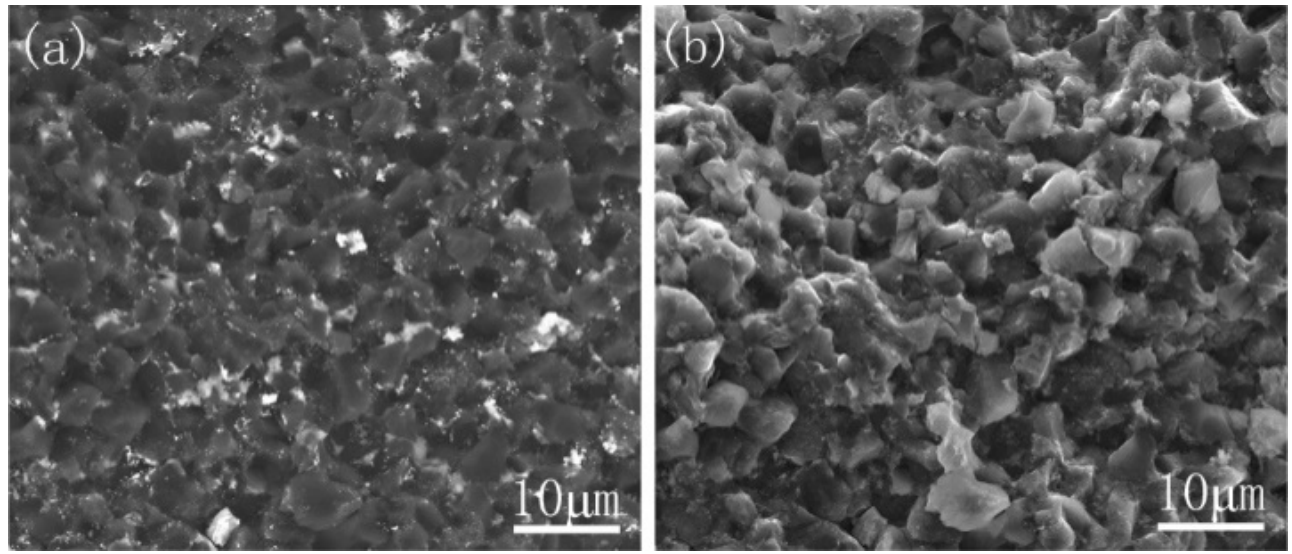

Figure 9. Three-point bending fracture of the cBN composite $(5 \mu \mathrm{m})$ : (a) BSED and (b) ETD.

To further illustrate the influences of binder particle size and grain size on the flexural strength of the composite, the XRD patterns of the TiAl powder before and after ball milling (Figure 2) were peak fitted. The grain size (D) was calculated by the Scherrer formula.

$$
\mathrm{D}=\frac{\mathrm{K} \lambda}{\mathrm{B} \cos \theta}
$$

where $\mathrm{K}=$ Scherrer constant (0.89), $\theta=$ Bragg diffraction angle, $\lambda=$ wavelength, and $\mathrm{B}=$ full width at half maximum.

The average grain size of the TiAl powder before and after ball milling were calculated as $41.83 \mathrm{~nm}$ and $6.10 \mathrm{~nm}$, respectively. Therefore, the grain size was significantly reduced after ball milling. It can be inferred that when the ball-milled TiAl powder was used to bond $\mathrm{cBN}$, its fine grain size could strengthen the sintered cBN composite. Meanwhile, the reduction in the particle size further strengthened the composite due to the dispersion strengthening by making the distribution of binder particles more uniform. These two strengthening effects improved the flexural strength of the cBN composite.

\section{Conclusions}

(1) In the microstructure of the cBN composite prepared by adopting $\gamma$-TiAl alloy as the binder, the $\mathrm{TiAl}_{3}, \mathrm{TiN}$ and $\mathrm{TiB}_{2}$-phase diffusion layers were distributed on the $\mathrm{cBN}$ matrix. A thin layer of $\mathrm{AlN}$ and $\mathrm{AlB}_{2}$ was distributed at the $c B N$ grain boundary, forming $\mathrm{cBN} / \mathrm{AlN}, \mathrm{AlB}_{2} / \mathrm{TiN}$, and $\mathrm{TiB}_{2} / \mathrm{TiAl}_{3}$-layered structures. The density of the composite reached $99 \%$ after sintering.

(2) Ti atoms reacted with cBN continuously. During the reaction, $\mathrm{Al}$ atoms were continuously rearranged to both sides of the interface reaction layer by forming $\mathrm{AlN}$ and $\mathrm{AlB}_{2}$ phases, which were located at the boundary, while the $\mathrm{TiAl}_{3}$ phase appeared on the inner side.

(3) The particle size and oxygen content of TiAl significantly affected the mechanical properties of the $\mathrm{CBN}$ composite. The grain size of the powder after ball milling was reduced from $41.83 \mathrm{~nm}$ to $6.10 \mathrm{~nm}$, leading to an increase in the strength of the cBN composite, owing to the fine-grain strengthening mechanism. The distribution of the binder was more uniform due to the decrease in its particle size. When the particle size decreased from $29 \mu \mathrm{m}$, the flexural strength of the composite further increased. The composite prepared from TiAl, with an average particle size of $5 \mu \mathrm{m}$, had a peak flexural strength of $360 \mathrm{MPa}$.

(4) TiAl avoided the inverse conversion of $\mathrm{cBN}$ to $\mathrm{hBN}$ caused by the local heating of the combustion reaction, which retained part of the unreacted intermetallic compound binder. However, the preparation process before sintering significantly increased the oxygen content, which led to the oxidation of TiAl during the sintering process.

Author Contributions: Conceptualization, W.Z.; methodology, Y.L.; formal analysis, Y.L. and Y.P.; investigation, Y.L.; resources, G.F. and B.L.; writing—original draft preparation, Y.L.; writing—review 
and editing, Y.P., G.F. and B.L.; supervision, W.Z.; project administration, W.Z.; funding acquisition, W.Z. All authors have read and agreed to the published version of the manuscript.

Funding: This research was funded by Regional Innovation and Development Joint Fund of the National Natural Science Foundation of China (grant No. U20A20236) and the Natural Science Foundation of Hunan Province (grant No. 2020JJ4738).

Institutional Review Board Statement: Not applicable.

Informed Consent Statement: Not applicable.

Data Availability Statement: The data presented in this study are available upon request from the corresponding author.

Acknowledgments: We thank LetPub (www.letpub.com) for its linguistic assistance during the preparation of this manuscript.

Conflicts of Interest: The authors declare no conflict of interest.

\section{References}

1. Tang, H.; Wang, M.; He, D.; Zou, Q.; Ke, Y.; Zhao, Y. Synthesis of nano-polycrystalline diamond in proximity to industrial conditions. Carbon 2016, 108, 1-6. [CrossRef]

2. Poulachon, G.; Bandyopadhyay, B.P.; Jawahir, I.S.; Pheulpin, S.; Seguin, E. Wear behavior of CBN tools while turning various hardened steels. Wear 2004, 256, 302-310. [CrossRef]

3. Li, L.; Zhao, Y.; Sun, K.; Ji, H.; Feng, D.; Li, Z. Composition, microstructure and mechanical properties of cBN-based composites sintered with AlN-Al-Ni binder. Ceram Int. 2018, 44, 16915-16922. [CrossRef]

4. Barsoum, M.W. The MN+1AXN phases: A new class of solids: Thermodynamically stable nanolaminates. Prog. Solid State Chem. 2000, 28, 201-281. [CrossRef]

5. Xie, H.; Deng, F.; Wang, H.; Liu, J.; Han, S.; Feng, F. Study of the proportioning design method and mechanical properties of a cBN-TiN composite. Int. J. Refract Met. Hard. Mater. 2020, 89, 105209. [CrossRef]

6. Li, L.; Zhou, A.; Wang, L.; Li, S.; Wu, D.; Yan, C. In situ synthesis of cBN-Ti ${ }_{3} \mathrm{AlC}_{2}$ composites by high-pressure and hightemperature technology. Diam. Relat. Mater. 2012, 29, 8-12. [CrossRef]

7. Yue, Z.; Yang, L.; Gong, J.; Gao, J. Synthesis and comparison of Two cBN composites with starting ternary carbide binders. J. Mater. Eng. Perform. 2018, 27, 2124-2130. [CrossRef]

8. Benko, E.; Klimczyk, P.; Mackiewicz, S.; Barr, T.L.; Piskorska, E. cBN-Ti ${ }_{3} \mathrm{SiC}_{2}$ composites. Diam. Relat. Mater. 2004, 13, 521-525. [CrossRef]

9. Semiatin, S.L.; Seetharaman, V.; Weiss, I. Hot workability of titanium and titanium aluminide alloys-An overview. Mater. Sci. Eng. A 1998, 243, 1-24. [CrossRef]

10. KIM, Y.Y. Microstructural evolution and mechanical properties of a forged gamma titanium aluminide alloy. Acta Metall. Mater. 1992, 40, 1121-1134. [CrossRef]

11. Perrut, M.; Caron, P.; Thomas, M.; Couret, A. High temperature materials for aerospace applications: Ni-based superalloys and $\gamma$-TiAl alloys. R. Phys. 2018, 19, 657-671. [CrossRef]

12. Liang, B.; Wang, Z.; Zhang, Y. Effect of c-BN size and content on the self-propagating high-temperature synthesis of c-BN composites bonded with Ti-Al-C system multiphase products. High Temp. Mater. Proc. 2016, 35, 369-374. [CrossRef]

13. Liu, Y.; Sun, A.; Zhong, S.; Mo, P.; Wu, Y. Effect of AlTi content on mechanical properties of in-situ synthesized PcBN composites. Diam. Relat. Mater. 2020, 109, 108068. [CrossRef]

14. Yuan, Y.; Cheng, X.; Chang, R.; Li, T.; Zang, J.; Wang, Y.; Yu, Y.; Lu, J.; Xu, X. Reactive sintering cBN-Ti-Al composites by spark plasma sintering. Diam. Relat. Mater. 2016, 69, 138-143. [CrossRef]

15. Bača, L'; Stelzer, N. Adapting of sol-gel process for preparation of TiB2 powder from low-cost precursors. J. Eur. Ceram. Soc. 2008, 28, 907-911. [CrossRef]

16. Carlone, C.; Lakin, K.M.; Shanks, H.R. Optical phonons of aluminum nitride. J. Appl. Phys. 1984, 55, 4010-4014. [CrossRef]

17. Jallad, K.N.; Ben-Amotz, D. Raman chemical imaging of tribological nitride coated (TiN, TiAlN) surfaces. Wear 2020, 252, 956-969. [CrossRef]

18. Deng, W.; Deng, F.; Liu, R.; Peng, Z.; Ma, X.; Xu, Z. Interfacial bonding mechanism of high-pressure sintered Al-Ti-cBN composites. Diam. Relat. Mater. 2019, 91, 29-33.

19. Li, Y.; Li, S.; Lv, R.; Qin, J.; Zhang, J.; Wang, J.; Wang, F.; Kou, Z.; He, D. Study of high-pressure sintering behavior of cBN composites starting with cBN-Al mixtures. J. Mater. Res. 2008, 23, 2366-2372. [CrossRef]

20. Rong, X.Z.; Yano, T. TEM investigation of high-pressure reaction-sintered cBN-Al composites. J. Mater. Sci. 2004, 39, 4705-4710. [CrossRef]

21. Rong, X.Z.; Tsurumi, T.; Fukunaga, O.; Yano, T. High-pressure sintering of cBN-TiN-Al composite for cutting tool application. Diam. Relat. Mater. 2002, 11, 280-286. [CrossRef]

22. Deng, F.; Liu, R. The process and mechanism of high pressure sintering of PcBN. Superhard. Mater. Eng. 2008, 3, 5-8. 
23. Barin, I.; Knacke, O.; Kubaschewski, O. Thermochemical Properties of Inorganic Substances: Supplement; Springer Science \& Business Media: Berlin/Heidelberg, Germany, 2013; p. 33.

24. Walmsley, J.C.; Lang, A.R. A transmission electron microscope study of a cubic boron nitride-based compact material with AIN and AIB2 binder phases. J. Mater. Sci. 1987, 22, 4093-4102. [CrossRef]

25. Zhang, A.; Li, Z.; Li, Z.; Zhu, Y. Preparation and characterization of $\mathrm{SiO}_{2}-\mathrm{Al}_{2} \mathrm{O}_{3}-\mathrm{Na}_{2} \mathrm{O}$ glass coated cBN abrasive particles via sol-gel route. J. Solgel. Sci. Technol. 2009, 49, 6-11. [CrossRef] 